\title{
OLIVIER MAILLART, Énigmes, Cinéma
}

\section{Luana Doni}

\section{CpenEdition \\ Journals}

\author{
Edizione digitale \\ URL: https://journals.openedition.org/studifrancesi/23402 \\ DOI: $10.4000 /$ studifrancesi.23402 \\ ISSN: 2421-5856

\section{Editore} \\ Rosenberg \& Sellier

\section{Edizione cartacea} \\ Data di pubblicazione: 1 avril 2020 \\ Paginazione: 235-236 \\ ISSN: 0039-2944

\section{Notizia bibliografica digitale} \\ Luana Doni, «Olivier mallLart, Énigmes, Cinéma», Studi Francesi [Online], 190 (LXIV | I) | 2020, online dal \\ 01 mai 2020, consultato il 03 août 2021. URL: http://journals.openedition.org/studifrancesi/23402 ; \\ DOI: https://doi.org/10.4000/studifrancesi.23402
}

Questo documento è stato generato automaticamente il 3 août 2021.

\section{(c) (†)}

Studi Francesi è distribuita con Licenza Creative Commons Attribuzione - Non commerciale - Non opere derivate 4.0 Internazionale. 


\title{
OLIVIER MAILLART, Énigmes, Cinéma
}

\author{
Luana Doni
}

\section{NOTIZIA}

OLIVIER MAILLART, Énigmes, Cinéma, Paris, Marest Éditeur, 2018, 118 pp.

1 Come sostenuto da Susan Sontag, citata in apertura del volume, uno dei caratteri intrinseci della natura umana è la passione per l'interpretazione. Tale volontà di andare al di là del già-dato, di sapere tutto, mette l'uomo in condizioni di percepire il senso profondo di ogni cosa come un enigma da risolvere.

2 Sfruttando dunque quanto scritto da Sontag nel saggio Contre linterprétation, Olivier Maillart si interroga su questo tratto distintivo del genere umano, interrogando in primo luogo la settima arte, centro di gravità e sintesi suprema del voyeurismo imperante.

3 Il cinema in quanto manifestazione del desiderio di vedere, di addentrarsi dentro un labirinto di segni da decifrare, porta in scena non soltanto la spettacolarità dell'enigma, ma anche quella figura d'eccellenza senza la quale non potrebbe esistere alcuna forma artistica, ossia, "l'uomo che guarda", lo spettatore.

4 È nella letteratura, nello specifico in Balzac, che l'A. trova il punto di partenza dell'indagine intorno allo spettatore; La maison du Chat-qui-pelote, racconto che apre quel vasto insieme rappresentato da La Comédie humaine, introduce, a partire dal secondo paragrafo, la figura nascosta e immobile di un uomo che guarda e che, con la precisione maniacale di un archeologo, trascina la storia all'interno del suo punto di vista.

5 Attraverso questa mise en abyme dell'arte di osservare, Balzac invita il lettore a sviluppare quella coscienza da ermeneuta, da scrutatore di quanto si cela dietro la superficie opaca delle cose.

6 L'avvento del cinema non ha fatto altro che alimentare la morbosità dello spettatore, sostituendo la parola con l'immagine e non solo: l'occhio del cinema, come sostiene 
Walter Benjamin, ha saputo raggiungere ciò che l'occhio umano non è mai riuscito ad afferrare.

7 Il cinema obbliga lo spettatore ad una sorta di "scuola dello sguardo", ad un avanzare nella vita secondo immagini cinematografiche che annientano in un certo qual modo il senso dello stupore anche di fronte alla tragedia; tutto è già stato visto, o meglio, riprodotto, spettacolarizzato.

8 L'esempio del mondo che assume le sembianze dell'enigma è ben rappresentato da $L a$ finestra sul cortile di Alfred Hitchcock, che decide di ridurre il proprio eroe interamente al suo sguardo, generando così una sequenza infinita nella quale lo spettatore cinematografico diventa lo spettatore di uno spettatore.

Ecco che allora il cinema attinge forza dalla letteratura poliziesca nella quale l'eroe è proprio lo spettatore. Blow up di Michelangelo Antonioni dà voce e corpo a quest'immagine chiave della modernità cinematografica: è infatti la camera e non l'occhio a dar vita al mistero, a cogliere l'impercettibile e a svelare la verità.

Blow up di Antonioni apre una lunga serie di pellicole in cui il protagonista assume il ruolo dell'investigatore. Maillart ricorda tra gli altri La Conversazione di Francis Ford Coppola, Profondo rosso di Dario Argento, fino ad arrivare a Minority Report di Steven Spielberg, in cui l'assimilazione tra personaggio-investigatore e spettatore è assoluta.

11 Spostando il discorso sull'aspetto più tecnico della resa cinematografica dell'"occhio che guarda", nel capitolo intitolato L'œeil divisé, Maillart fa l'esempio di quello che in gergo viene chiamato "split-screen" o tecnica dello schermo diviso. Scopo di questo modo particolare di resa dell'immagine è quello di dare allo spettatore la suggestione di possedere uno sguardo ubiquo sulla scena. Il fantasma del palcoscenico di Brian De Palma rappresenta il grado massimo di utilizzazione di questo tipo di montaggio il quale poggia sulla certezza instillata nello spettatore che il cinema sia in grado di "mostrare tutto".

Dall'ubiquità dell'occhio che guarda, si passa al disorientamento dello stesso, attraverso l'uso del found footage, una tecnica di ripresa basata sulla sequenza diretta di metraggi preesistenti, montati nuovamente in contesti inediti. Yervant Gianikian e Angela Ricci Lucchi sono i realizzatori di decine di film che sfruttano la tecnica del found footage, al fine di concentrarsi su quello che per loro è l'enigma più grande: la Storia.

13 Ma il cinema non è soltanto lo strumento che mostra il mondo, è anche quello che lo racconta. Quando entra in gioco la narrazione, ecco che l'inchiesta assume le sembianze di un itinerario labirintico come quello portato sullo schermo da Shining di Stanley Kubrick, in cui l'enigma narrativo è rafforzato dalla presenza del soprannaturale, oppure il labirinto spazio-temporale de La strategia del ragno di Bernardo Bertolucci, in cui lo spaesamento dello spettatore è generato dall'andirivieni tra le due epoche del racconto.

Il cinema è anche tradimento, come illustra bene Maillart nell'ultima parte del volume. Sotto le spoglie di una lente d'ingrandimento su di una realtà invisibile, il cinema mente e, soprattutto quando si parla di enigmi, la così detta "cattiva interpretazione" è un ostacolo ma anche una salvezza poiché soltanto una volta decifrato il falso si può giungere alla soluzione.

15 Ma questa, in fin dei conti, è la missione di ogni forma d'arte: dalla letteratura alla poesia, passando per il cinema, tutto ciò che si cerca costantemente di indagare è il mistero infinito del rapporto tra l'uomo e il mondo che lo circonda. 